\title{
Ultrasound mediated synthesis of ecofriendly zinc chalcogenates in "on water conditions"
}

\author{
Bonifacio Monti ${ }^{1}$, Luca Sancineto ${ }^{1}$, Laura Abenante ${ }^{1}$, Ester Giorgi ${ }^{1}$, Luana Bagnoli ${ }^{1}$, \\ Francesca Marini ${ }^{1}$, Eder Joao Lenardão ${ }^{2 *}$, Claudio Santi ${ }^{1 *}$ \\ (1) Department of Pharmaceutical Sciences University of Perugia-ITALY \\ (2) Universidade Federal de Pelotas (UFPel), P.O. Box 354, Pelotas 96010-900, Brazil
}

\begin{abstract}
Nucleophilic Selenium is a convenient strategy for the functionalization of organic substrates having electrophilic character. Among all the methods developed for their preparation, the reduction of the corresponding diselenides represents the most versatile procedure. Using these protocols selenolates were usually prepared in situ using atom expensive reducing agents such as $\mathrm{NaBH}_{4}$, $\mathrm{LiAlH}_{4}$, or metals (Na, Li) or metal hydride ( $\mathrm{NaH}$ ). We recently reported that zinc can be efficiently used to reduce Se-halogen bond affording bench stable regents such as $\mathrm{PhSeZnCl}$ that showed a strong rate acceleration in "on water" conditions for a number of reactions: alkyl, aryl, vinyl and acyl substitutions, ring-opening reactions of epoxides and aziridines and Michael type additions. We report now the use of Ultrasound irradiation for the oxidative insertion of zinc into Se-Se bond and the formation of the nucleophilic reagent PhSeZnSePh as a green strategy to avoid the use of useless halogens and increase the atom economy of the selenenylating species.
\end{abstract}

\section{Introduction}

Organoselenium chemistry is currently attracting the interest of several research groups also in consideration of many biological properties that were recently claimed and reported in literature for some selenium containing compounds such as antioxidants, hormetins, antidepressants, antimicrobials, inhibitors of enzyme and proteins like glutathione transferase (GSTP) and the NcP7, exploiting anticancer and anti-HIV activities.' Organoselenium moieties can be conveniently introduced using electrophilic, nucleophilic or radical selenium-centered reagents easily accessible starting from diselenides through oxidative, reductive or homolitic cleavage of the seleniumselenium bond. The use of nucleophilic selenium reagents is reported in literature using in situ generation protocols promoted by organomagnesium or organolithium species si $^{\mathrm{i}}$ or by using several metals as well as several reducing agents starting from diselenides.

In 2008 we reported two different protocols for the preparation of selenium centered nucleophilic species. The first one involved the zinc mediated reduction of diselenides in a biphasic system consisting in $10 \%$ aqueous solution of $\mathrm{HCl}$ and diethyl etheriii. This methodology has been applied by us and other authors in epoxides and aziridines ring opening reactions ${ }^{\text {iv }}$, hydrochalcogenation of triple bonds ${ }^{v}$ as well as in the formation of Selonocystine based peptide-derivatives ${ }^{\mathrm{vi}}$.

In the same year, a bench stable zinc selenate has been prepared starting from commercially available $\mathrm{PhSeCl}$ and $\mathrm{PhSeBr}{ }^{\text {vii }}$ through an oxidative zinc insertion in THF. The resulting $\mathrm{PhSeZnCl}$ and $\mathrm{PhSeZnBr}$ were successfully used in on water conditions and in some cases, it was demonstrated that the water (as normally happen for ionic liquids) can be recycled and reused without any significant decrease of the yield ${ }^{\text {viii. }}$

To increase the greenness of the process we take in consideration the oxidative insertion of zinc into the selenium-selenium bond of diphenyl diselenide. The resulting PhSeZnSePh will enable the optimization of the atom economy reducing the use of halogens especially chlorine. To improve the previously reported methodologies we used ultrasounds(US) for the activation of the zinc and the reduction of diselenide.

The direct energy derived from US wavelength is not able to produce a chemical reaction, but a series of longitudinal vibration allow a series of compression and rarefactions that can create cavities points into solvent molecules, like bubbles, in presence of air, dust or other particles. The 
most important effect of ultrasound derived from the lifetime of bubbles. They generally resist for few acoustic cycles and then they collapse, generating microjets that produce a local great change in temperature and pressure that influences chemical reactions.

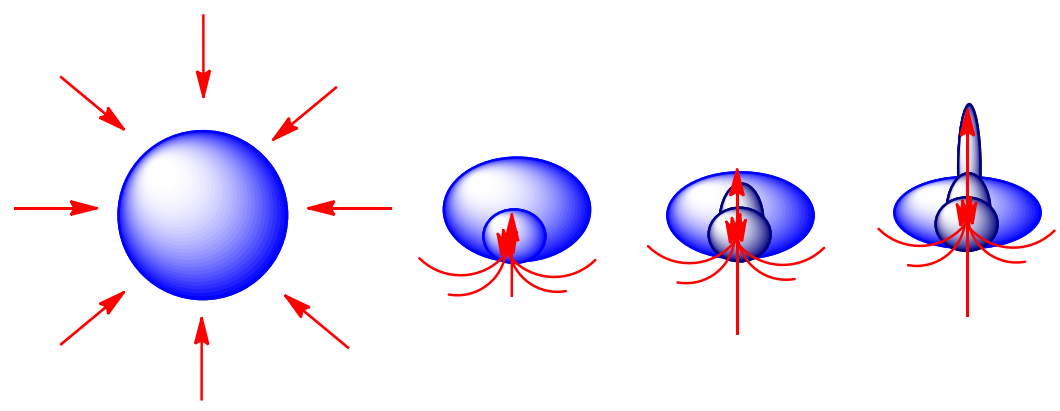

Figure 1 - Scheme for the microjets generation by ultrasound.

In 1979, Moon et al. Reported the first example of sonochemistry. They applied US to the saponification reactions of esters reducing the reaction time from 90 to 10 minutes and the reaction temperature from reflux to room temperature ${ }^{i x}$ and from this point a series of interesting applications have been reported ${ }^{\times}$xi xii. An important aspect is the ability of small bubbles microjets to erode metallic surfaces. This aspect has been described for the first time by Howkins ${ }^{\text {xiii }}$ and it has been applied with many metallic powders, including zinc ${ }^{\mathrm{xiv} x \mathrm{v}}$.

\section{Results and discussion}

Here we propose the first US-promoted synthesis of a zinc selenate.
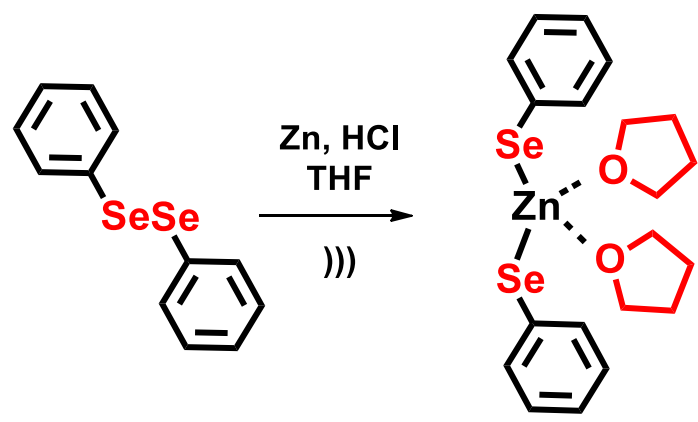

Scheme $\mathbf{1}$ - Synthesis of zinc selen olate $\mathbf{2}$ in THF under US conditions.

Starting from commercially available diphenyl diselenides $\mathbf{1}$, a slight excess of zinc is added in a tube (1.83 eq.) and a stoichiometric amount of aqueous solution of hydrochloric acid (10\%) in $1 \mathrm{~mL}$ of tetrahydrofuran under US for 15 minutes. The organic layer is removed under reduced pressure and a white solid is obtained (2). This one, analysed by ${ }^{77} \mathrm{Se}-\mathrm{NMR}$, showed a characteristic signal at $41 \mathrm{ppm}$, evidencing the presence of a nucleophilic selenium atom and a deep investigation by DFT calculation and NMR demonstrated that 2 molecules of solvents are probably responsible of this unusual stability (Scheme 1). At this point the addition of 1.5 equivalents of TMEDA $\left(N, N, N^{\prime}, N^{\prime}-\right.$ 
tetramethyl ethilendiammine) in toluene for 24 hours afforded the complex $\mathbf{3}$ that was purified by crystallization from Pyridine/heptane.

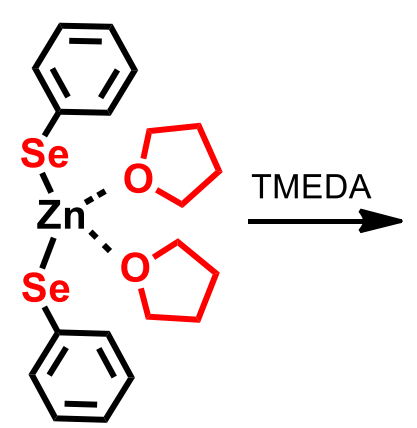

2

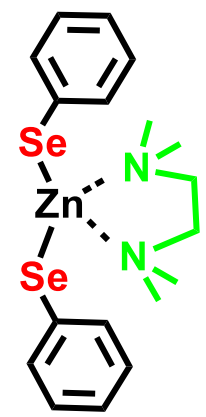

3

Scheme2 - Synthesis of zinc selenium complex 3

The reactivity of Santi's Reagents ( $\mathrm{PhSeZnBr}$ and $\mathrm{PhSeZnCl}$ ), the selenol/selenate mixture generated in situ in biphasic system as well as the complexes $\mathbf{2}$ and $\mathbf{3}$ were compared using as probe the ring

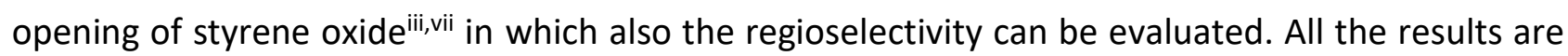
collected in Table 1.
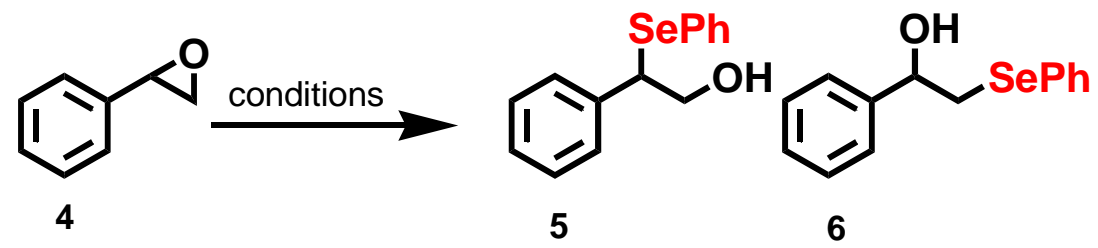

\begin{tabular}{|c|c|c|c|c|c|}
\hline Entry & Selenate & Condition & Time & Yield & $5 / 6$ \\
\hline 1 & $\mathrm{PhSeZnCl}$ & THF & $24 \mathrm{~h}$ & $100 \%$ & $88: 12$ \\
\hline 2 & $\mathrm{PhSeZnCl}$ & $\mathrm{H}_{2} \mathrm{O}$ & $2 \mathrm{~h}$ & $100 \%$ & $80: 20$ \\
\hline 3 & $\mathrm{PhSeZnBr}$ & THF & $24 \mathrm{~h}$ & $20 \%$ & $56: 44$ \\
\hline 4 & $\mathrm{PhSe})_{2} \mathrm{Zn}$ & Biphasic system & $4 \mathrm{~h}$ & $78 \%$ & $95: 5$ \\
\hline 5 & $\mathrm{PhSe})_{2} \mathrm{Zn}-\mathrm{THF}$ & Sonication $-\mathrm{H}_{2} \mathrm{O}$ & $30 \mathrm{~min}$. & $100 \%$ & $80: 20$ \\
\hline 6 & $\mathrm{PhSe})_{2} \mathrm{Zn}-\mathrm{THF}$ & Sonication - THF & $30 \mathrm{~min}$. & Traces & - \\
\hline 7 & PhSe) ${ }_{2} Z \mathrm{Zn}-\mathrm{TMEDA}$ & DCM & $6 \mathrm{~h}$ & Traces & - \\
\hline 8 & PhSe) ${ }_{2} \mathrm{Zn}-\mathrm{TMEDA}$ & $\mathrm{DCM}_{-} \mathrm{SiO}_{2}$ & $1 \mathrm{~h}$ & $28 \%$ & $77-23$ \\
\hline
\end{tabular}

Table 1 - Comparison of the reactivity of different selenates.

The reaction proceeds very well with $\mathrm{PhSeZnCl}$ (both in on water condition and in THF solution) and PhSeZnSePh in the biphasic system (entries 1, 2 and 4) affording a couple of regioisomers (5 and 6 ). In all the cases 5 was the major isomer because of the acidic condition (entry 4 and 8 ) and/or the Lewis acid character of the zinc in all the cases let favourable the ring opening reaction occurring in benzylic position. Interestingly the reaction in "on water" conditions are strongly accelerated but the reaction time could be further reduced under ultrasound irradiation. The TMEDA complexed resulted to be non-reactive and a slight acidic condition, obtained by the addition of silica, afforded the couple of isomers in $28 \%$ yield and a ratio of $77 / 23$. 
This latter evidence induced us to setup a flow and stop system in which the reagent $\mathbf{3}$, dispersed in silica was poured in the head of a silica gel column. Through the column was fluxed petroleum ether $(\mathrm{PE})$ as eluent at a flux rate of $5 \mathrm{~mL} / \mathrm{min}$ and the styrene oxide 4 , dissolved in petroleum ether, was injected in the flux. Dichloromethane (DCM) is finally used to elute the products from the column. At the end of the column the eluent was fractionated obtaining in one-pot reaction and purification of the products 5 and 6 that were obtained in 50\%yield and in a regioisomeric ratio of 89:11.

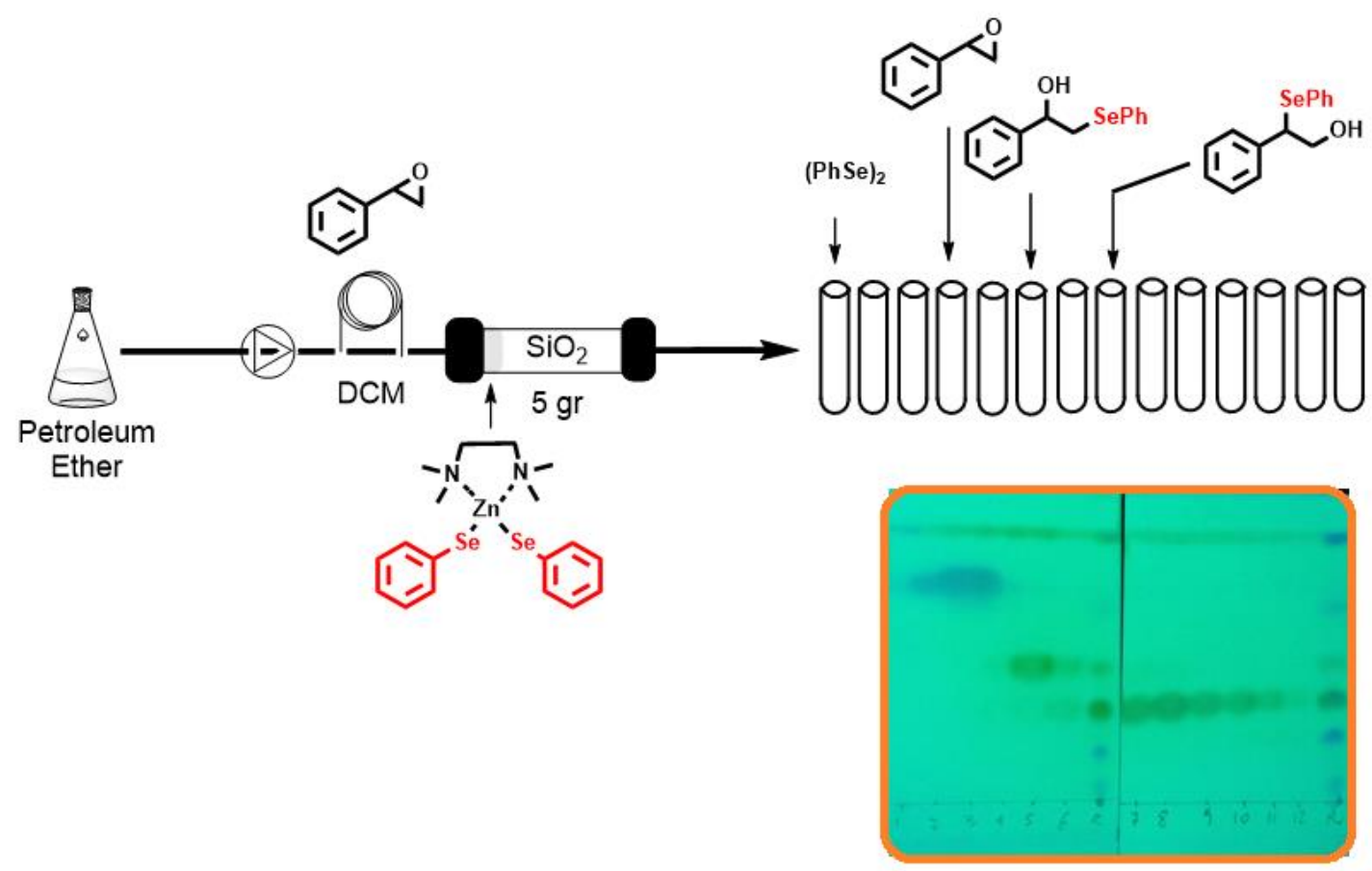

Figure 2 - "Flow and Stop" system, One -Pot Reaction and Purification

To the best of our knowledge only one other example was reported in literature in which selenium was used for a ring opening reaction using ultrasounds. In this case the basic conditions favoured the formation of the regioisomer $6^{\mathrm{xvi}}$.

Further investigations are currently in ongoing to better understand the applicability of this system, its scalability and the scope of the reaction. 


\section{References}

'S. Legnaioli, M. Piroddi, C. Tidei, C. Santi, F. Galli, Free Radical Biol. Med., 2012, 53, S112-S113.; L. Sancineto, A. Mariotti, L. Bagnoli, F. Marini, J. Desantis, N. Iraci, C. Santi, C. Pannecouque, O. Tabarrini, J. Med. Chem., 2015, 58, 9601-9614.

ii A. Krief, L. Havesi, Organoselenium Chemistry, Springer-Verlag, Berlin 1988; A. Krief, Comprehensive Organometallic Chemistry, B. M. Trost Ed., Pergamon Oxford, 1991, 85; T. Wirth, Comprehensive Organometallic Chemistry III; R. H. Crabtree, D. M. P. Mingos, Elsevier Oxford, 2006, 457.

iii S. Santoro, L. Testaferri, M. Tiecco, C. Santi, Synlett, 2008, 10, 1471-1474.

${ }^{i v}$ R. S. Schwab, E. E. Alberto, S. M. Salman, J. Vargas, J. B. Azeredo, A. L. Braga, Tetrahedron Lett., 2009, 50, 2309-2311.

${ }^{\vee}$ C. Tidei, L. Sancineto, L. Bagnoli, B. Battistelli, F. Marini, C. Santi, Eur. J. Org. Chem., 2014, 5968-5975.

vi S. Jr. Flemer, Prot. Pept. Lett., 2014, 21, 1257-1264; S. Jr. Flemer, J. Pept. Sci., 2015, 21, 53-59.

vii S. Santoro, B. Battistelli, L. Testaferri, M. Tiecco, C. Santi, Eur. J. Org. Chem., 2008, 32, 5387-5390.

viii C. Santi, B. Battistelli, L. Testaferri, M. Tiecco, Green Chem., 2012, 14, 1277-1280.

ix S. Moon, L. Duchin, J. V. Cooney, Tetr. Lett., 1979, 20, 3917-3920.

${ }^{x}$ B. Hee Han, P. Boudjouk, Tetr. Lett., 1982, 23, 1643-1646.

xi E. Lukevics, V. N. Gevorgyan, Y. S. Goldberg, Tetr. Lett., 1984, 25, 1415-1416.

xii J. L. Luche, C. Petrier, C. Dupuy, Tetr. Lett., 1984, 25, 753-756.

xiii S. D. Howkins, J. Acoust. Soc. Am., 1966, 39, 55-61.

${ }^{\text {xiv }}$ K. S. Suslick, S. J. Doctycz, J. Am. Chem. Soc., 1989, 111, 2342-2344.

${ }^{\mathrm{x}} \mathrm{M}$. Isobe, S. Kondo, M. Nagasawa, T. Goto, Chem. Lett., 1977, 6, 679-682.

xi X. Zheng, Q. Ke, T. Cheng, J. of Chemical Research, 2011, 522-524. 